\title{
Comparison of left ventricle mechanical dyssynchrony parameters in ischemic and non- ischemic patients using ${ }_{13} \mathrm{~N}-\mathrm{NH}_{3} \mathrm{PET} / \mathrm{CT}$
}

\author{
Angelica Mazzoletti, ${ }^{\mathrm{a}}$ Domenico Albano, ${ }^{\mathrm{a}}$ Francesco Bertagna, \\ Claudio Tinoco Mesquita, ${ }^{b}$ and Raffaele Giubbini ${ }^{\mathrm{a}}$ \\ a Nuclear Medicine, University of Brescia and Spedali Civili Brescia, Brescia, Italy \\ b Universidade Federal Fluminense, Niterói, RJ, Brazil
}

Received Jun 3, 2020; accepted Nov 30, 2020

doi: $10.1007 / \mathrm{s} 12350-020-02466-\mathrm{w}$

Background-Aim. The relationship between perfusion pattern and stress-induced changes in Left Ventricular Mechanical Dyssynchrony (LVMD) has been previously described with controversial results using stress-rest perfusion imaging studies. The aim of this study was to assess the relationship between perfusion pattern and stress-induced changes in LVMD usingo regadenoson/rest13N-NH3 PET/CT.

Methods. There were 74 patients who underwent stress-rest 13N-NH PET/CT from January 2014 to October 2018 excluding patients with left bundle branch block, ventricular pacing and myocardial necrosis. The patients were divided into those with reversible perfusion defects at stress (Ischemic group, $n=18$ ) and patients without reversible perfusion defects (nonischemic group, $n=56$ ). The LVMD parameters included: phase standard deviation (PSD) and phase histogram bandwidth (PHB), after stress and at rest. The $\triangle$ PSD (post-stressPSDrestPSD) and $\triangle P H B$ (post-stressPHB - restPHB) were calculated to measure stress-induced changes in LVMD.

Results. There were no significant differences in LVMD parameters between post-stress and at rest in both groups. The PSD post-stress, $\triangle$ PSD and PHB post-stress were significantly higher in the ischemic group.

Conclusions. Using a vasodilator as a stress, the PSD and PHB post-stress and $\triangle$ PSD were significantly higher in the ischemic patients than the non-ischemic group, while there were no significant differences in each cohort between stress and rest indices. ( $J$ Nucl Cardiol 2022;29:1248-53.)

Key Words: Dyssynchrony $\cdot$ ammonia $\cdot$ PET/CT $・ 13 N-N H 3$ PET/CT $\cdot$ regadenoson • myocardial perfusion $\cdot$ myocardial blood flow

See related editorial, pp. 1254-1256

Supplementary Information The online version of this article (h ttps://doi.org/10.1007/s12350-020-02466-w) contains supplementary material, which is available to authorized users.

The authors of this article have provided a PowerPoint file, available for download at SpringerLink, which summarises the contents of the paper and is free for re-use at meetings and presentations. Search for the article DOI on SpringerLink.com.

Reprint requests: Angelica Mazzoletti, Nuclear Medicine, University of Brescia and Spedali Civili Brescia, Brescia, Italy; mazzolettiangelica@gmail.com

1071-3581/\$34.00

Copyright (C) 2021 The Author(s)

\section{INTRODUCTION}

Left ventricular mechanical dyssynchrony (LVMD) is defined as the differences in the timing of onset of contraction between the different myocardial segments and it may have prognostic value for risk stratification. ${ }^{1,2}$ LVMD by phase analysis of gated myocardial perfusion imaging (MPI) has emerged as a robust, automated, and reproducible technique to quantify mechanical dispersion. ${ }^{3} 13 \mathrm{~N}$-ammonia $\left({ }_{13} \mathrm{~N}-\mathrm{NH}_{3}\right)$ may be used in PET/TC imaging and allows quantification of 
coronary flow reserve (CFR), myocardial blood flow (MBF) LV perfusion, wall motion, LV function and LVMD in patients with Coronary artery disease (CAD). Previous studies ${ }^{4-6}$ with different radiotracers such as Rubidium-82 and 99mTc-sestamibi, demonstrated that stress-induced ischemia causes dyssynchronous contraction in the ischemic region, leading to worsening of LVMD, but no previous study has examined the use of ${ }_{13} \mathrm{~N}-\mathrm{NH}_{3}$. The aim of this study was to evaluate the relationship between perfusion pattern and stress-induced changes in LVMD using ${ }_{13} \mathrm{~N}-\mathrm{NH}_{3}$ PET/CT after regadenoson stress and at rest.

\section{METHODS}

\section{PET/CT Imaging and Interpretation}

Patients were in fasting state for stress studies. Maximal vasodilatation was obtained after I.V. injection of $400 \mathrm{mg}$ of regadenoson over 10 seconds in the right antecubital vein followed by a bolus administration of a standard dose of $370 \mathrm{MBq}$ of $13 \mathrm{NH} 340$ seconds after the end of regadenoson injection. The PET studies were acquired in 3D and list mode for 10 minutes starting acquisition immediately before $13 \mathrm{NH} 3$ injection by a discovery PET/CT 690 (GE Healthcare, Milwaukee, h Wisconsin, USA). A low-dose CT attenuation correction (140 kV, 120-150 mA) was acquired for optimal imaging position on a CT scout scan and for attenuation correction. PET images were corrected for attenuation. The reconstruction was performed using iterative algorithms OSEM (Ordered-subset expectation maximization) with 3 iterations and 24 subsets, filter cut-off $6 \mathrm{~mm}$ and $128 \times 128$-pixel matrix). Gated images were reconstructed in 16 bins and the dynamic images and in 32 frames for both stress and rest $(24 \times$ 10 s, $4 \times 30$ s, $4 \times 60$ s). The perfusion pattern was assessed after iterative reconstruction of tomographic slices and evaluated as recommended by the American Society of Nuclear Cardiology. The SDS was determined by 4-DM Corridor software package (INVIA, Ann Arbor, Michigan), using an Institutional gendermatched normal database. We calculated the SSS and the SRS as the sum of the respective scores of all 17 segments, and derived SDS as the difference between SSS and SRS, served as a measure of reversibility. A SDS $\leq 1$ was considered as normal. ${ }^{7}$ Aminophylline was injected at the end of the stress part $(240 \mathrm{mg}$ in 10 $\mathrm{mL}$ ). Stress examination was performed with continuous ECG monitoring to assess heart rate increase induced by regadenoson stimulation. Two hours after the stress examination, rest studies were acquired for 10 minutes in 3D and list mode after the injection of a standard dose of $370 \mathrm{MBq}$ of ${ }_{13} \mathrm{~N}-\mathrm{NH}_{3}$. Quantitative $\mathrm{MBF}$ and CFR were determined using the PMOD software package (PMOD Technologies Ltd., Zurich, Switzerland). The CFR was calculated as the ratio of hyperemic to resting MBF; CFR e"' 2.5 was considered as normal. The SDS as well as the MBF and CRF was evaluated for the global left ventricle (LV) and for the three coronary territories using a 17-segment model according to the American Society of Nuclear Cardiology recommendations. The PMode software package provides automatically measures of rest, stress MBF, and CFR for global, segmental (according to the 17 segment model), and for the three main vascular territories, identified as anterior, anteroseptal, and apical segments for the left anterior descending coronary artery, inferior and infero-septal segments for the right coronary artery, and of lateral segments for the left circumflex, respectively.

\section{Patient Features}

Seventy-four patients (44 men; 30 women), average age $62 \pm 12 ., 72$ (range 36-89) who had stress-rest ${ }_{13} \mathrm{~N}$ $\mathrm{NH}_{3}$ PET/CT from January 2014 to October 2018 at our department were enrolled. Patients with left bundle branch block, ventricular pacing, previous revascularization and myocardial necrosis were excluded from the study. Patients were divided into two groups accordingly MPI results: those with reversible myocardial perfusion defects at stress (ischemic group, n. 18) and those without reversible perfusion defects (non ischemic group, n. 56). In each group, we compared the demographics such as age, sex, smoke history, obesity (evaluated as BMI >30), history of hypertension, diabetes, hyperlipidemia and kidney failure. LVMD parameters included phase histogram bandwidth (PHB) and phase standard deviation (PSD). PHB represents the range of degrees of the cardiac cycle during which $95 \%$ of myocardium is starting to contract; PSD is the standard deviation of the range. The $\triangle \mathrm{PSD}$ (evaluated as the difference between post- stress PSD and rest PSD) and $\triangle \mathrm{PHB}$ (- the difference between post- stress PHB and PHB at rest) were calculated to measure stressinduced changes in LVMD.

\section{Statistical Analysis}

Statistical analyses were performed out using MedCalc Software version 18.1. The descriptive analysis of categorical variables are characterized by the calculation of simple and relative frequencies, while the numeric variables by median, mean, minimum and maximum values.

Either student's t test or Mann-Whitney test was used to compare quantitative data between different 
groups, when required. Chi square $(\chi 2)$ test was used to compare proportions. A $P$ value $<0.05$ was considered to indicate statistical significance.

\section{RESULTS}

The demographics are in Table 1. Non significant differences were observed between ischemic and nonischemic groups except of sex and history of diabetes. The LVMD parameters are in Table 2. The LVMD parameters (PSD and PHB) were not significant differences between stress and rest in each group. All LVMD parameters were higher in the ischemic patients compared to non- ischemic ones, but only PSD post- stress$\triangle \mathrm{PSD}$ - and PHB post stress were statistically significant. The correlation matrix between LVMD and perfusion pattern is shown in Table 3. Examples from both groups are shown in Figures 1 and 2.

\section{DISCUSSION}

Intraventricular dyssynchrony reflects inhomogeneous timing of contraction of different myocardial segments, caused by disturbed myocyte stimulation or impaired contractility. ${ }^{8,9}$ It is helpful to recognize that even structurally normal hearts exhibit some degree of non-uniformity in contraction due to its complex spatial and geometric architecture. Contraction movements depend on the complex distribution of myocardial fibers within the epicardial and endocardial regions as they are oriented longitudinally through the long axis of the heart and circumferentially within the mid-wall region. This arrangement allows for a complex contractile movement which involves both longitudinal and circumferential fibers from apex to base during systolic activation. Due to this complex fiber architecture and to the presence of His-Purkinje system, which allow electrical activation, systolic contraction can be well executed allowing efficient pump function. It is not surprising that in an ischemic heart abnormal temporal electrical activation of the complex myocardial fiber architecture reduces pump efficiency and cardiac performance. ${ }^{8}$ As a result of that abnormal activation loading, LVMD parameters increase and reflects a balance of forces, with the region that is activated early being unable to withstand the stress generated by the late-activated LV segments. ${ }^{10-12}$ The regional wall contractions are not effectively converted to pressure build-up in the left ventricle, but

Table 1. Epidemiological and clinical parameters between ischemic and non-ischemic patients

\begin{tabular}{llll}
\hline & Ischemic group (18) & Non ischemic group (56) & P Value \\
\hline Average age & $67 \pm 18$ & $63 \pm 13$ & \\
Men & $15 / 18$ & $29 / 56$ & 0.017 \\
Women & $3 / 18$ & $27 / 56$ & \\
Hypertension & $9 / 18$ & $34 / 56$ & 0.29 \\
Hyperlipidemia & $9 / 18$ & $28 / 56$ & 0.5 \\
Diabetes & $6 / 18$ & $9 / 56$ & 0.04 \\
BMI>30 & $3 / 18$ & $7 / 56$ & 0.39 \\
Kidney failure & $1 / 18$ & $2 / 56$ & \\
Smoke & $3 / 18$ & $14 / 56$ & 0.68 \\
Smoke in the past & $5 / 18$ & $16 / 56$ & 0.45 \\
\hline
\end{tabular}

Table 2. Left ventricle mechanical dyssynchrony parameters between ischemic and non-ischemic patients

\begin{tabular}{lccc}
\hline & Ischemic group (18) & Non ischemic group (56) & P Value \\
\hline PSD stress & $6.01 \pm 6.57$ & $4.16 \pm 2.68$ & 0.003 \\
PSD rest & $4.6 \pm 2.8$ & $4.28 \pm 1.06$ & 0.48 \\
SPSD & $1.41 \pm 3.74$ & $-0.11 \pm 1.62$ & 0.003 \\
PHB stress & $24.22 \pm 32.52$ & $17.46 \pm 7.07$ & 0.008 \\
PHB rest & $18.55 \pm 14.14$ & $15.67 \pm 5.65$ & 0.09 \\
$\Delta$ PHB & $5.66 \pm 18.38$ & $1.78 \pm 1.41$ & 0.07 \\
MBF stress & $1.9 \pm 0.03$ & $2.4 \pm 3.4$ & 0.04 \\
\hline
\end{tabular}


Table 3. Correlation between dyssynchrony parameters with perfusion parameters in different groups

\begin{tabular}{|c|c|c|c|c|c|c|}
\hline & \multicolumn{2}{|c|}{ Entire population $n 74$} & \multicolumn{2}{|c|}{ Ischemic group $n 18$} & \multicolumn{2}{|c|}{$\begin{array}{l}\text { Non-ISchemic group } n \\
56\end{array}$} \\
\hline & $\begin{array}{l}\text { Correlation } \\
\text { coefficient }\end{array}$ & $\begin{array}{c}P \\
\text { Value }\end{array}$ & $\begin{array}{l}\text { Correlation } \\
\text { coefficient }\end{array}$ & $\underset{\text { Value }}{P}$ & $\begin{array}{l}\text { Correlation } \\
\text { coefficient }\end{array}$ & $\underset{\text { Value }}{P}$ \\
\hline $\begin{array}{l}\text { PSD stress vs } \\
\text { SSS }\end{array}$ & 0.264 & 0.059 & -0.001 & 0.998 & 0.294 & 0.098 \\
\hline $\begin{array}{l}\text { PHB stress vs } \\
\text { SSS }\end{array}$ & 0.227 & 0.064 & -0.036 & 0.890 & 0.276 & 0.056 \\
\hline$\triangle \mathrm{PSD}$ vs SDS & 0.134 & 0.277 & 0.021 & 0.934 & -0.174 & 0.224 \\
\hline$\triangle \mathrm{PHB}$ vs SDS & 0.178 & 0.148 & 0.080 & 0.759 & 0.064 & 0.657 \\
\hline$\triangle \mathrm{PSD}$ vs CFR & -0.134 & 0.252 & -0.372 & 0.128 & 0.083 & 0.536 \\
\hline$\triangle \mathrm{PHB}$ vs CFR & -0.120 & 0.306 & -0.221 & 0.377 & -0.012 & 0.928 \\
\hline
\end{tabular}

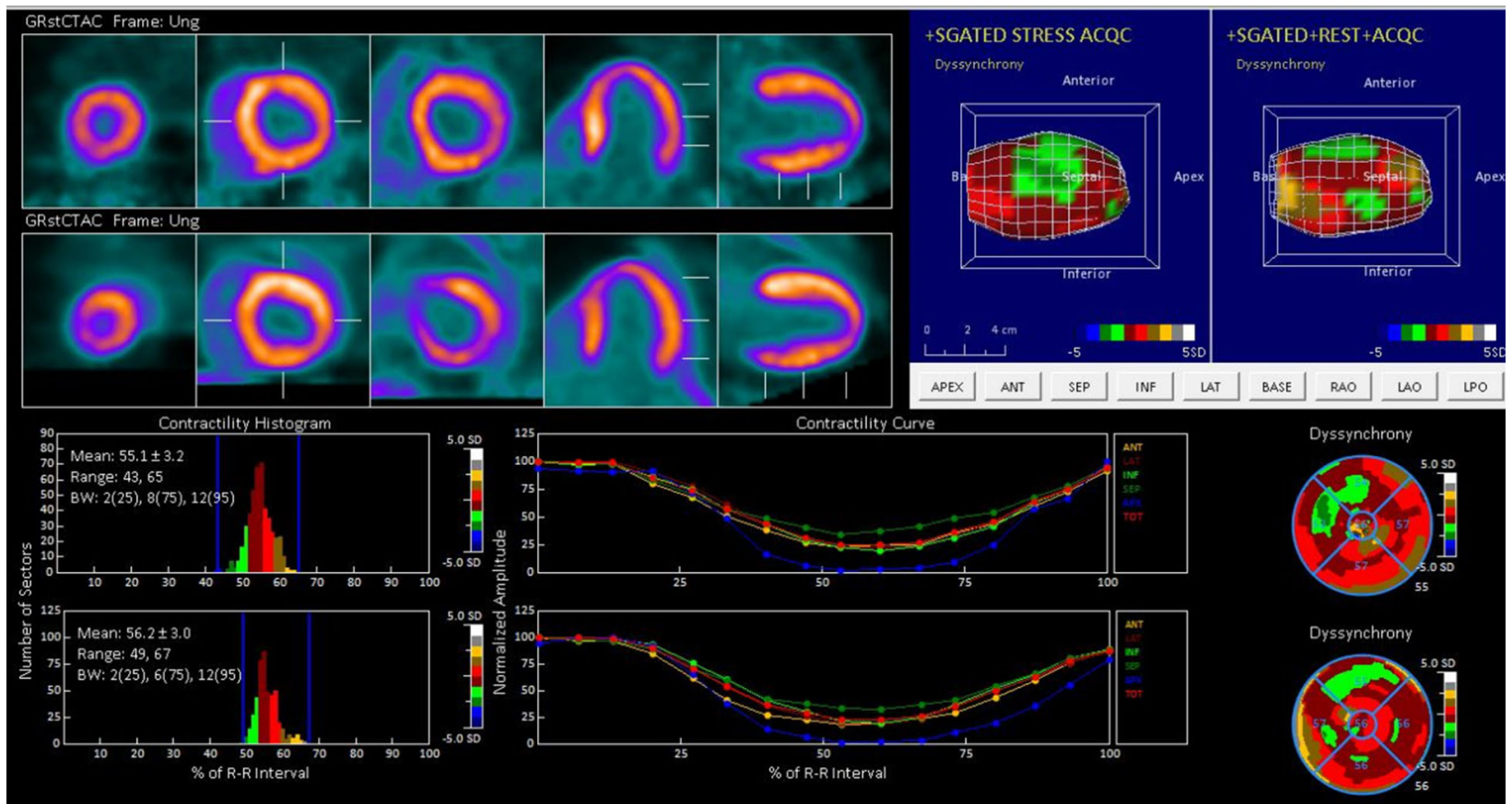

Figure 1. A representative case of Ischemic Patient. Woman, 75- years old, without history of cardiovascular risk factors.

rather cause substantial blood volume shifts within the $\mathrm{LV}$ cavity. The overall result is a decrease in LV pumping efficiency. ${ }^{9-12}$ Several new imaging techniques are proving useful for diagnosis of LV dyssynchrony and PET/TC represents a useful method to quantify LVMD parameters. Different radiotracers allow the study of both myocardial perfusion and myocardial metabolism such as radioactive ${ }_{13} \mathrm{~N}-\mathrm{NH}_{3}, \mathrm{H}_{2} \mathrm{O}_{15},{ }_{82} \mathrm{Rb}$. While water is freely diffusible without being retained from myocardial tissue, ammonia and rubidium present different pharmacokinetic features and they are usually retained in the myocardial tissue depending on myocardial blood flow. While rubidium crosses the myocyte cell membrane mainly by active diffusion, ammonia crosses the myocyte cell membrane by passive diffusion. Unlike technetium radiotracers, ammonia-PET/CT images are acquired immediately after stress induction by regadenoson injection, at maximum peak of vascular 


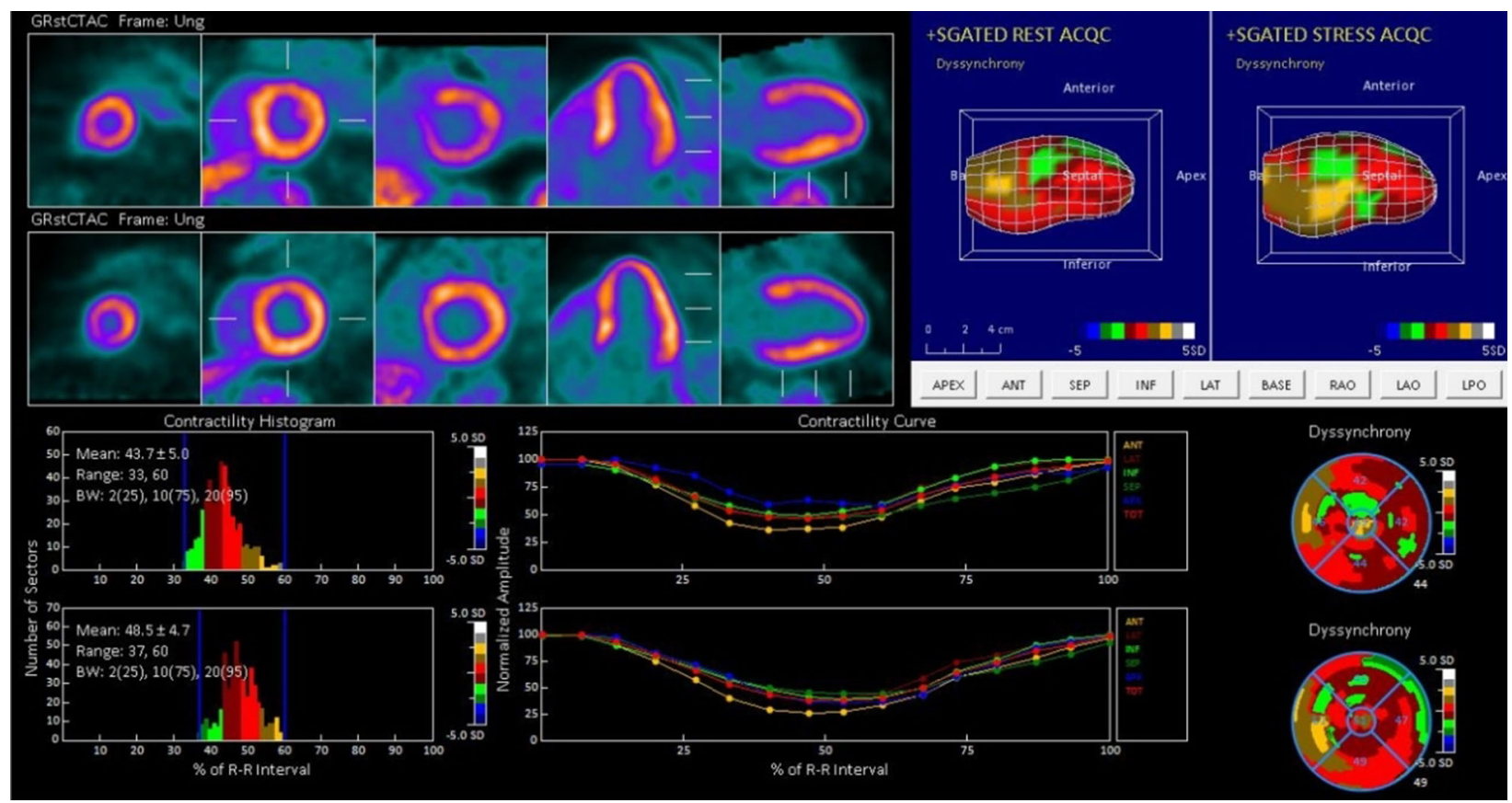

Figure 2. A representative case of Non- Ischemic Patient. Man, 52 years old, without history of cardiovascular risk factors.

dilatation and it allow for the evaluation of absolute myocardial perfusion and mechanical synchrony at real peak hyperemic stress. Myocardial extraction of the $\mathrm{PET} / \mathrm{TC}$ radiotracers at rest is higher than the radiotracers used with SPECT and it depends on myocardial blood flow. When compared to adenosine, regadenoson has been shown to be non-inferior for identifying perfusion defects ${ }^{13}$ and providing prognostic data. ${ }^{14-19}$ Our study shows that LVMD is different in ischemic and non-ischemic patients though in each group they were comparable at rest and post stress. The study has limitations as it is retrospective and the ischemic group has small number of patients. However, it is a proof of principle that our protocol could be used to study LVMD in addition to other variables such as perfusion, function and $\mathrm{MBF}$.

\section{NEW KNOWLEDGE GAINED}

13N-NH3 PET/TC represent a reliable method for estimating myocardial dyssynchrony parameters. The presence of ischemia is confirmed by a non-synchronous contraction of myocardial tissue and a decrease of myocardial blood flow, parameters evaluated after pharmacological stress test conducted with the use of regadenoson.

\section{Funding}

Open access funding provided by Università degli Studi di Brescia within the CRUI-CARE Agreement.

\section{Disclosure}

The Authors do not have any conflict of interest to declare.

\section{Ethical standards}

This human study has been approved by the institutional ethics committee and has therefore been performed in accordance with the ethical standards laid down in the 1964 Declaration of Helsinki and its later amendments.

\section{Informed consent}

All persons gave their informed consent prior to their inclusion in the study.

\section{Open Access}

This article is licensed under a Creative Commons Attribution 4.0 International License, which permits use, sharing, adaptation, distribution and reproduction in any medium or format, as long as you give appropriate credit to the original author(s) and the source, provide a link to the Creative Commons licence, and indicate if changes were made. The images or other third party material in this article 
are included in the article's Creative Commons licence, unless indicated otherwise in a credit line to the material. If material is not included in the article's Creative Commons licence and your intended use is not permitted by statutory regulation or exceeds the permitted use, you will need to obtain permission directly from the copyright holder. To view a copy of this licence, visit http://creativecommons.org/licenses/by/4.0/.

\section{References}

1. Nagueh SF. Mechanical dyssynchrony in congestive heart failure: diagnostic and therapeutic implications. J Amer Coll Cardiol. 2008;51:18-22.

2. Shah AM, Solomon SD. Mechanical dyssynchrony: a risk factor but not a target. Eur Heart J. 2016;37:60-2.

3. Chen J, Garcia EV, Bax JJ, et al. SPECT myocardial perfusion imaging for the assessment of left ventricular mechanical dyssynchrony. J Nucl Cardiol. 2011;18:685-94.

4. Pazhenkottil AP, et al. Left ventricular dyssynchrony assessment by phase analysis from gated PET-FDG scans. J Nucl Cardiol. 2011;18:920-5. https://doi.org/10.1007/s12350-011-9411-y.

5. Wael AlJaroudi M, Alraies Chadi, Menon Venu, et al. Predictors and incremental prognostic value of left ventricular mechanical dyssynchrony response during stress-gated positron emission tomography in patients with ischemic cardiomyopathy. J Nucl Cardiol. 2012;19:958-69. https://doi.org/10.1007/s12350-012-959 2-z.

6. Zhang F, Yang W, Wang Y, et al. Is there an association between hibernating myocardium and left ventricular mechanical dyssynchrony in patients with myocardial infarction? Hell J Nucl Med. 2018;21:28-34. https://doi.org/10.1967/s002449910704.

7. Giubbini R, Peli A, Milan E, et al. Comparison between the summed difference score and myocardial blood flow measured by 13N-ammonia. J Nucl Cardiol. 2017;25:1621-8. https://doi.org/ 10.1007/s12350-017-0789-z.

8. Cheng A, Helm RH, Abraham TP. Pathophysiological mechanisms underlying ventricular dyssynchrony. Europace. 2009;11:v10-4. https://doi.org/10.1093/europace/eup272.
9. Bleeker GB, Bax JJ, Steendijk P, et al. Left ventricular dyssynchrony in patients with heart failure: pathophysiology, diagnosis and treatment. Nat Clin Pract Cardiovasc Med. 2006;3:213-9. h ttps://doi.org/10.1038/ncpcardio0505.

10. Prinzen FW, et al. Mapping of regional myocardial strain and work during ventricular pacing: experimental study using magnetic resonance imaging tagging. $\mathrm{J}$ Am Coll Cardiol. 1999;33:1735-42.

11. Spragg DD, et al. Regional alterations in protein expression in the dyssynchronous failing heart. Circulation. 2003;108:929-32.

12. Kass D. Ventricular resynchronization: pathophysiology and identification of responders. Rev Cardiovasc Med. 2003;4:S3-13.

13. Iskandrian AE, Bateman TM, Belardinelli L, et al. Adenosine versus regadenoson comparative evaluation in myocardial perfusion imaging: results of the ADVANCE phase 3 multicenter international trial. J Nucl Cardiol. 2007;14:645-58.

14. Iqbal FM, Hage FG, Ahmed A, et al. Comparison of the prognostic value of normal regadenoson with normal adenosine myocardial perfusion imaging with propensity score matching. JACC Cardiovasc Imaging. 2012;5:1014-21.

15. Bhatti S, Hakeem A, Dhanalakota $S$, et al. Prognostic value of regadenoson myocardial single-photon emission computed tomography in patients with different degrees of renal dysfunction. Eur Heart J Cardiovasc Imaging. 2014;15:933-40.

16. Hage FG, Ghimire G, Lester D, et al. The prognostic value of regadenoson myocardial perfusion imaging. J Nucl Cardiol. 2015;22:1214-21.

17. Farzaneh-Far A, Shaw LK, Dunning A. Comparison of the prognostic value of regadenoson and adenosine myocardial perfusion imaging. J Nucl Cardiol. 2015;22:600-7.

18. El-Hajj S, AlJaroudi WA, Farag A, et al. Effect of changes in perfusion defect size during serial regadenoson myocardial perfusion imaging on cardiovascular outcomes in high-risk patients. $\mathbf{J}$ Nucl Cardiol. 2016;23:101-12.

19. Doukky R, Fughhi I, Campagnoli T, et al. The prognostic value of regadenoson SPECT myocardial perfusion imaging in patients with end-stage renal disease. J Nucl Cardiol. 2017;24:112-8.

Publisher's Note Springer Nature remains neutral with regard to jurisdictional claims in published maps and institutional affiliations. 